\title{
Numerical Analysis of the Biogeochemical Parameters in the Bay of Bengal
}

\author{
Saswati Deb ${ }^{1,2}$ and Arun Chakraborty ${ }^{1}$ \\ 1. Centre for Oceans, Rivers, Atmosphere and Land Sciences, Indian Institute of Technology, Kharagpur 721302, India \\ 2. School of Marine Sciences, University of Maine, Orono, ME 04469-5706, USA
}

\begin{abstract}
Oceanic nutrient cycling plays a key role in understanding how oceanic biogeochemical parameters respond in varying physical and anthropogenically controlled processes. OA (Objective Analysis) of monthly climatology of WOA13 (World Ocean Atlas 13) nutrient data of $5 \mathrm{~km}$ resolution called Nutrient-Climo has been done in this paper for analyzing the nutrient-rich region in the BOB (Bay of Bengal) and the mechanisms of physical forces were examined using six years (2002-2007) global ocean monthly analysis datasets based on the SODA v2.0.4 (Simple Ocean Data Assimilation package). The upwelled zones established from the circulation pattern were well synchronized with the nitrate rich zones. The POC (particulate organic carbon) of $5 \mathrm{~km}$ resolution has been analyzed from MODIS (Moderate-resolution Imaging Spectroradiometer) data and Chl a (Chlorophyll $a$ ) concentration SeaWiFS (Sea-viewing Wide Field-of-view Sensor) data of $9 \mathrm{~km}$ resolution are used to predict the productive zones in the BOB. In this paper, we examined that $\mathrm{Chl} a$ concentration (above $0.5 \mathrm{mg} / \mathrm{m}^{3}$ ) is found during the post-monsoon followed by winter in the north-western, north-eastern coast and head BOB as the source of nutrients is also supplementary due to high input of litter and sediment associated nutrients that are released during estuarine transport.
\end{abstract}

Key words: OA, Nutrient-Climo, Chl $a$, POC, MODIS, SeaWiFS.

\section{Introduction}

Observational results from different surveys [1-3] and ship-drift studies [4] have revealed distinctive features of surface circulation and seasonally reversing coastal currents in the BOB (Bay of Bengal). Even though several studies are investigated in the BOB, but many small mesoscale features along with nutrient distribution are not well understood due to scarcity of in-situ data, which influence the productivity of the BOB. Hence, the development of a high-resolution multiscale nutrient dynamic model is necessary to set up a high resolution biogeochemical model for the BOB to understand the key features regulating the regional distribution of bloom.

The BOB is influenced by heavy rainfall and freshwater discharges from the adjoining rivers. A strong stratified surface layer is formed during summer due to high SST (sea surface temperature)

Corresponding author: Saswati Deb, post-doctoral research associate, research fields: ocean modeling and data analysis. and above reasons. This strong stratified layer restricting the turbulent wind induced vertical mixing to a depth of less than $20 \mathrm{~m}$ and also limiting the mixing of nutrients from below, into the upper layers and thus making BOB less productive in summer [5].

The freshwater discharge and physical processes influence the seasonality of bacterioplankton regime of the BOB [6]. During the summer monsoon, the biological productivity is influenced by mesoscale and basin scale physical processes [7-8]. Phytoplankton becomes intensified by cyclones in the BOB during the northeast monsoon [9]. A special survey on station-wise distribution of nutrients has been done [10] to understand the nutrient distribution near the surface and mixed layer of the BOB but the precise description of high resolution regional distribution of nutrients in spatial and monthly scales has not been reported yet for the BOB.

In this paper, a high resolution monthly climatology of nutrients is constructed and the statistical analysis 
of the physical parameters has been presented. Box-wise biological response and nutrient distribution for the BOB were explained. The relationship between nutrients and physical parameters has also been analyzed statistically for four boxes to find out the appropriate zones of biological productivity.

This paper is arranged section-wise. The section 2 briefly describes the data and methodology used in this study. Results and discussion are represented in section 3. The summaries of these scientific studies are concluded in section 4 .

\section{Data and Methodology}

\subsection{Data Used}

In this paper, WOA13 (World Ocean Atlas 13) datasets are used, which are set of objectively analyzed (quarter degree grid) climatological fields of different chemical parameters like phosphate, silicate, and nitrate [11] at standard depth levels. WOA13 also contains associated statistical fields of observed oceanographic profile data interpolated to standard depth levels.

\subsection{The Objective Analysis Technique}

The OA technique [12-13] is an interpolation technique or method which is used to obtain a regular gridded field from the scattered observations. This method has been used to develop a high resolution ( 5 $\mathrm{km} \times 5 \mathrm{~km}$ ) climatology dataset of nutrients and currents for the BOB called Nutrient-Climo for the $\mathrm{BOB}$ which helps in analyzing the new features in comparison to the WOA13 climatology and SODA. These new climatology data provide us high resolution and good-quality data of nutrients and current at all standard depth levels providing detailed information in the coastal region and open sea.
Construction of a high resolution nutrient data is a first step towards the setup of a biogeochemical model for the BOB. OA interpolates the fields to the new grid by keeping the dynamical feature information intact [13] in an optimal statistical way, which improves its results compared to the direct interpolation method.

\section{Results and Discussion}

\subsection{Analysis of the Seasonality of Nutrient-Climo for} the $B O B$

During January, a weak anticyclonic circulation is formed centered at $\sim 17.8^{\circ} \mathrm{N}, 88^{\circ} \mathrm{E}$ which is accompanied by nitrate poor region. Fig. 1 of January month is supporting these results. In January, nitrate (Fig. 1), phosphate (Fig. 2) and silicate (Fig. 3) are found to be in low amount at the surface where anticyclonic circulations are more prevalent and match well with the vertical velocity (figure not shown here) of January representing downwelling zones. During this month, two other small scales anticyclonic features are also observed at $\sim 13.7^{\circ} \mathrm{N}, 82^{\circ} \mathrm{E}$ and $\sim 11.8^{\circ} \mathrm{N}, 86.9^{\circ} \mathrm{E}$ but the intensification is low. In between these anticyclonic circulations, there are also two cyclonic circulations with very low strength. In the month of February, anticyclonic circulation starts to intensify at $\sim 13.9^{\circ} \mathrm{N}, 82^{\circ} \mathrm{E}$. Then the current moves along the northwest coastal region of $\mathrm{BOB}$ accompanying high flux of nitrate and phosphate but silicate has been observed quite low in that region.

During March, WBC (Western Boundary Current) accompanied by anticyclonic gyres is captured in Fig 1 of March. The coastal boundary current near the head BOB is responsible for the influx of nitrate in this region. There may be another possible reason for the high nitrate in this region of which one may be the

Table 1 Multiscale OA parameters.

\begin{tabular}{lll}
\hline OA parameters & $\begin{array}{l}\text { Climatology large-scale } \\
(\mathrm{km})\end{array}$ & $\begin{array}{l}\text { Meso-scale } \\
(\mathrm{km})\end{array}$ \\
\hline Zero-crossing $(\mathrm{x} / \mathrm{y})$ & $300 / 300$ & $150 / 150$ \\
Radius of influence $(\mathrm{x} / \mathrm{y})$ & $150 / 150$ & $75 / 75$ \\
\hline
\end{tabular}



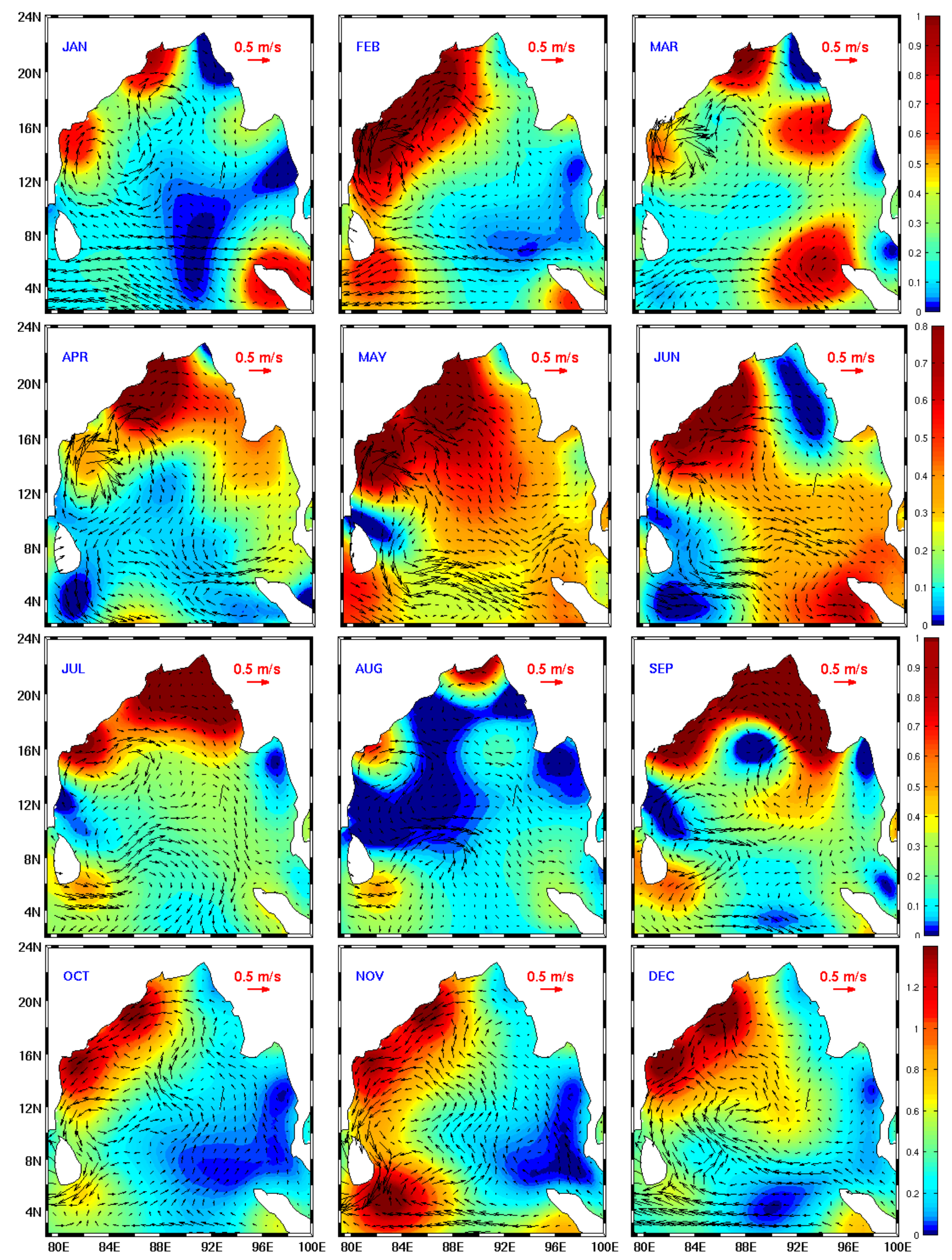

Fig. 1 Monthly climatology of nitrate (in $\mu \mathrm{M}$ ) for the BOB. The vectors are currents (in $\mathrm{m} / \mathrm{s}$ ). 

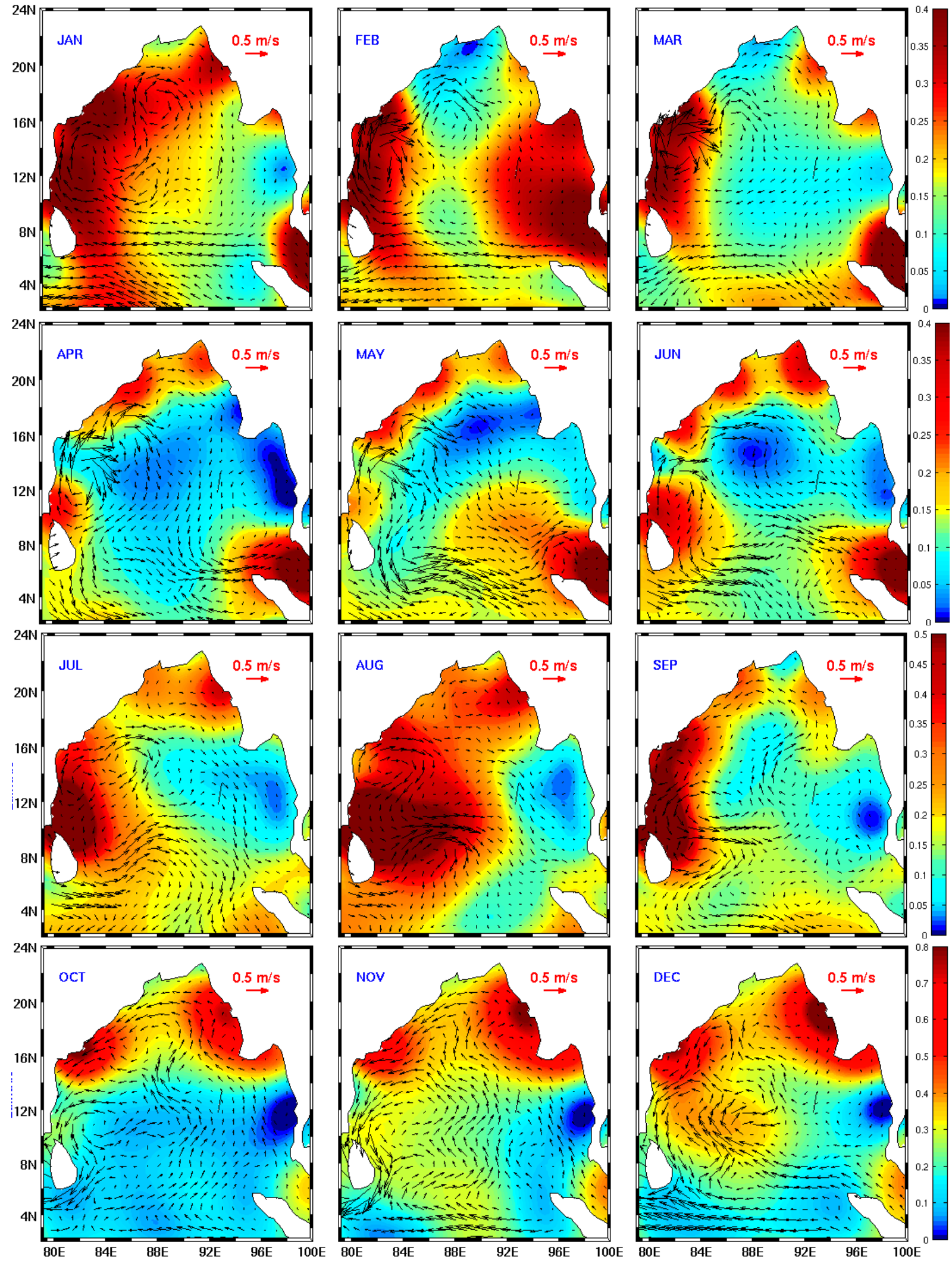

Fig. 2 Monthly climatology of phosphate (in $\mu \mathrm{M}$ ) for the BOB. The vectors are currents (in $\mathrm{m} / \mathrm{s}$ ). 
effluents of anthropogenic sources coming from the industries situated along the river bank and the other may be the decay of organic matter. This is one of the highly populated regions. Phosphate and silicate are found low towards the head of the BOB. Therefore, the Chl $a$ (Chlorophyll a) bloom is found to be low but considerably high in nitrate rich region of Hooghly Estuary throughout this period. Different studies evidenced that EPV (Ekman Pumping Velocity) is responsible for the phytoplankton bloom during the northeast monsoon. The bloom in the open ocean is caused by upwelling mainly driven by EPV [9].

During summer monsoon, especially in July followed by August, the half basin-scale anticyclonic gyres in the southern part of BOB, illustrate positive correlation between nutrients and EPV. The cyclonic eddy in the northern BOB, supplemented with nutrient-rich water showed positive correlation with EPV and negative correlation with SSH. In Fig. 3 of August, the silicate discharge is observed high (above $16 \mu \mathrm{mol} / \mathrm{L}$ ) resulting from the influx of river discharge carried by different river sources, especially from Ganga, Brahmaputra, Mahanadi and Irrawaddy. So during this season, silicate concentration (Fig. 3) is found considerably high on the head and northeast coast of BOB whereas phosphate concentration (Fig. 2 ) is high towards the head and northwest of BOB.

During the post-monsoon usually in October, high nutrients have been observed near the coastal area. The BOB is mainly dominated by cyclonic gyre with strong currents in the western coast during November that creates the East Indian Coastal Current (EICC) to flow southward and also influenced by weak anticyclonic gyres. High production of bloom [9] is observed during this season (October-November) as all the three components (nitrate, phosphate and silicate) are found in substantial quantity. The key physical processes influencing high bloom production are seasonal circulation in the $\mathrm{BOB}$, wind setup and EPV. During northeast monsoon, seasonal circulation and EPV bring nutrient-rich deeper water to surface and strong winds generally mix well the water at surface and subsurface layer resulting in high bloom production.

So to understand the role of nutrients in the biological response of $\mathrm{BOB}$, regional distribution of Chl $a$ along with particulate organic carbon is also important to study, which is discussed in the next sub-section.

\subsection{Monthly Variation of Chl $a$ and POC}

Based on the analysis of nutrient distribution and other scientific study [14] the BOB is divided into four boxes (Fig. 4) as follows,

(a) Box A: $78^{\circ}-90^{\circ} \mathrm{E}, 12^{\circ}-22^{\circ} \mathrm{N}$ (northwestern $\mathrm{BOB}$ );

(b) Box B: $90^{\circ}-100^{\circ} \mathrm{E}, 12^{\circ}-22^{\circ} \mathrm{N}$ (northeastern $\mathrm{BOB}$ );

(c) Box C: $78^{\circ}-90^{\circ} \mathrm{E}, 4^{\circ}-12^{\circ} \mathrm{N}$ (southwestern $\mathrm{BOB}$ );

(d) Box D: $90^{\circ}-100^{\circ} \mathrm{E}, 4^{\circ}-12^{\circ} \mathrm{N}$ (southeastern BOB).

The notable characteristic features of Box A and Box B in the northern part of BOB are the influence of the fresh water discharges and boundary currents. The Box $\mathrm{C}$ and Box D in the southern part of $\mathrm{BOB}$ are influenced by input from the Arabian Sea, the Indian Ocean as well as from the South China Sea via the Malacca Strait.

Surface monthly mean climatology of Chl $a$ and POC of BOB has been studied with a special emphasis on two months (March and October) are represented. The spatial plot of Chl $a$ in October (Fig. 5b) represents high $\left(0.35-0.85 \mathrm{mg} / \mathrm{m}^{3}\right)$ bloom around the Sri-Lanka dome and the coastal regions of BOB whereas in March, the reverse trend is found (Fig. 5a). The near-shore bloom abundance is due to the influence of boundary currents and vertical velocity during that period. Bloom abundance also depends upon the increase in Chl $a$ and the period of bloom onset. Furthermore, scientific study [15] revealed that 

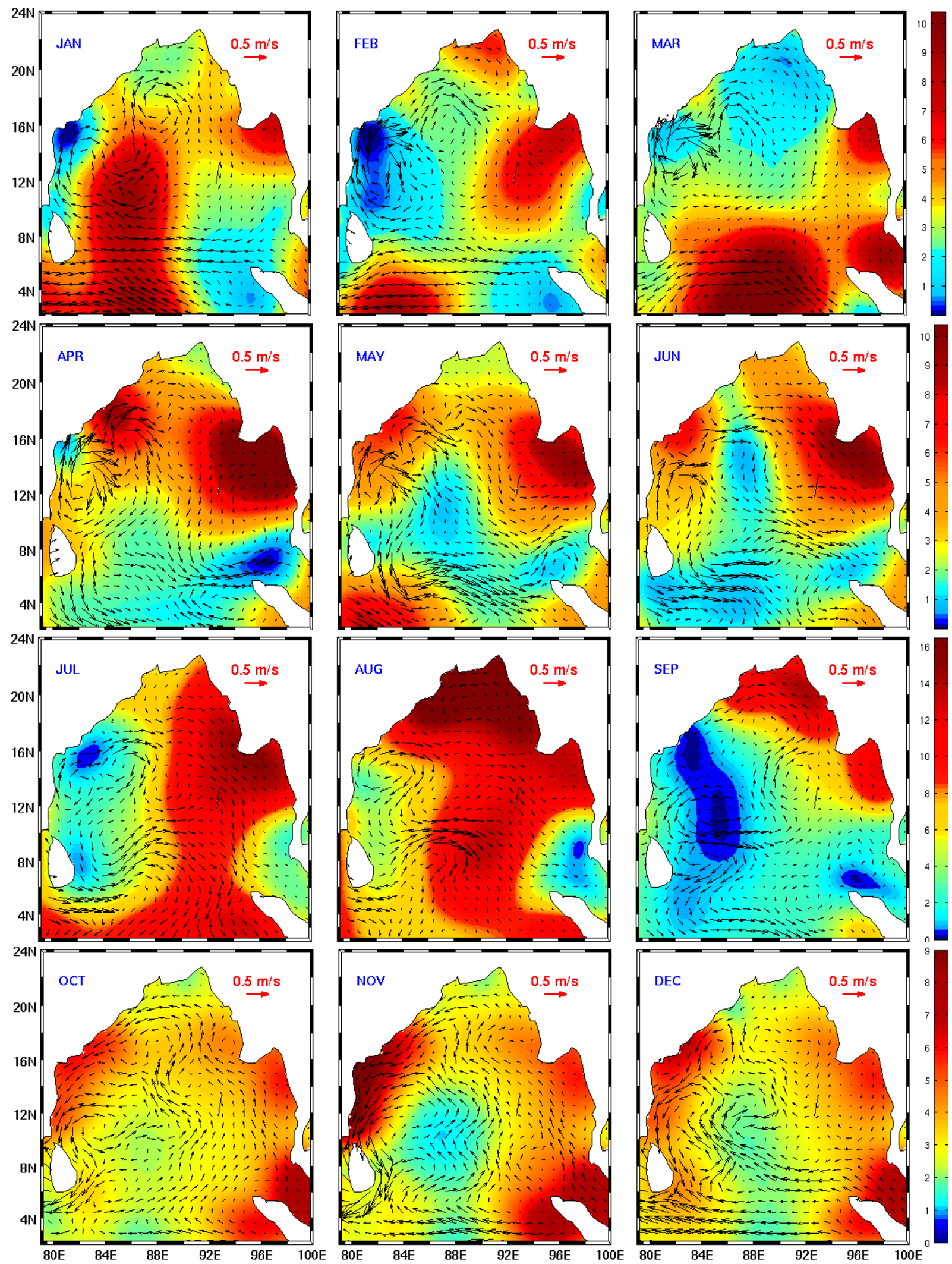

Fig. 3 Monthly climatology of silicate (in $\mu M$ ) for the BOB. The vectors are currents (in $\mathrm{m} / \mathrm{s}$ ). 


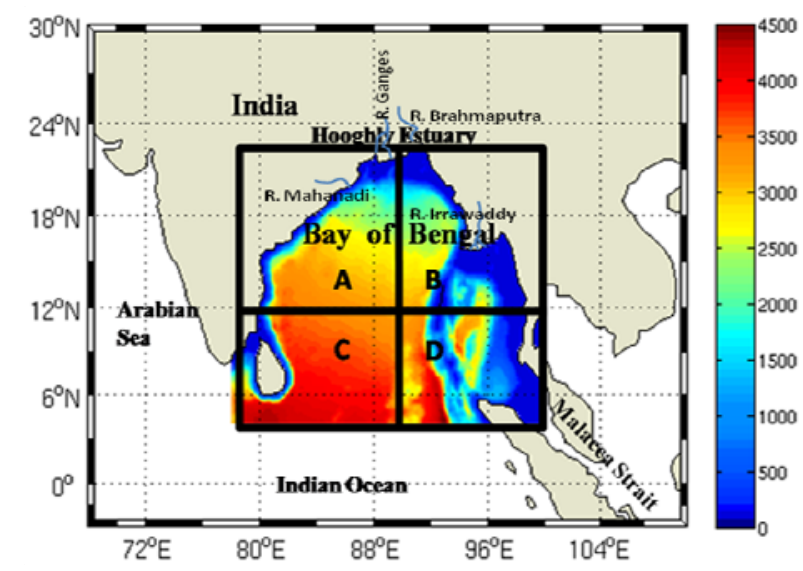

Fig. 4 The geographical locations of the BOB along with four boxes are considered. The shaded value denotes the bathymetry (in m) from ETOPO2.

regional variability of bloom pattern is linked with vertical and horizontal circulations driven by the monsoons. Besides the dynamical processes, the bloom rich regions are well co-related with DO [16-17] and linearly match with the POC distribution. To better understand the relation of bloom with the physical and biogeochemical parameters, a real-time

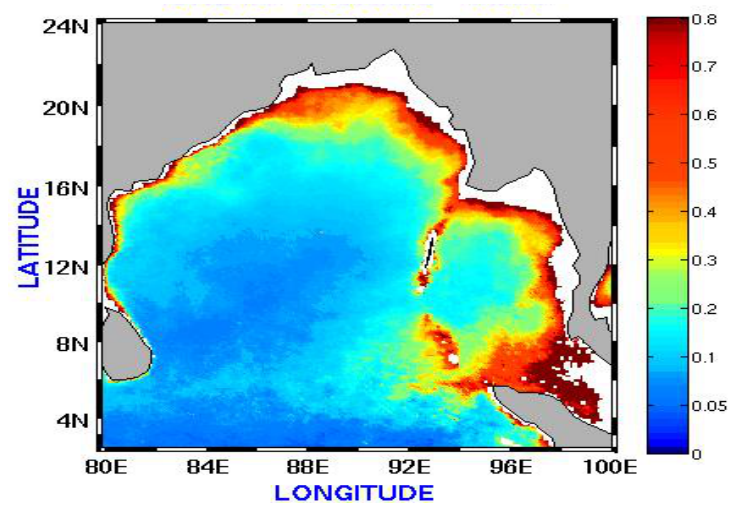

(a)

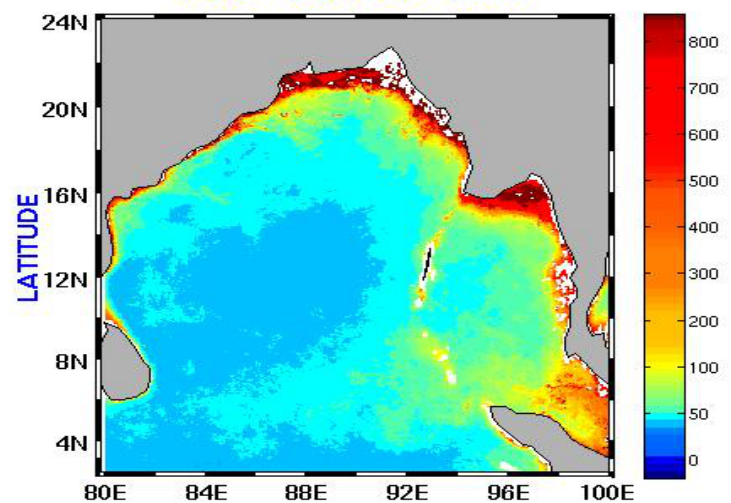

(c) data comparison needs to be witnessed, which is beyond the scope of the study.

However, seasonal cycles of Chl $a$ (Fig. 6) and POC (Fig. 7) have been illustrated for the four boxes to understand the region wise seasonal variability of $\mathrm{Chl} a$ and POC in BOB. POC distribution signifies the amount of decay matter. From the illustration of Chl $a$ (Figs. 6a and 6c) and POC (Figs. 7a and 7c) in March, low concentration of both the parameters is observed in the western BOB due to high SST and nutrient depletion. During the monsoon, blooming starts in the north-western BOB. The strong stratification layer formed during June in the head and northeast BOB due to freshwater discharge [5] does not allow the nutrients from below to come up. So this surface region became the Chl $a$ depleted region.

\subsection{Relation of Nutrients with EPV}

Fig. 8 depicts that nitrate is positively correlated with EPV except in few months. High EPV is accompanied

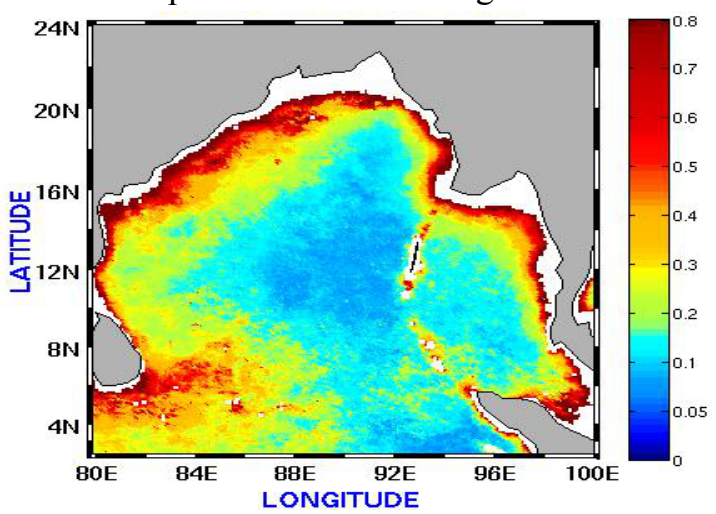

(b)

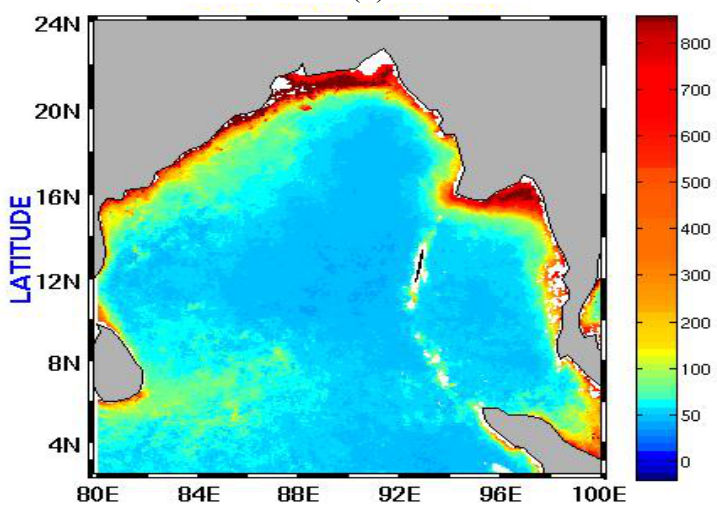

(d)

Fig. 5 Surface climatology of $\mathrm{Chl}$ a (upper panel) and POC (lower panel) concentration (mg/ $\left.\mathrm{m}^{3}\right)$ during March (a) and (c) and October (b) and (d). 
a)

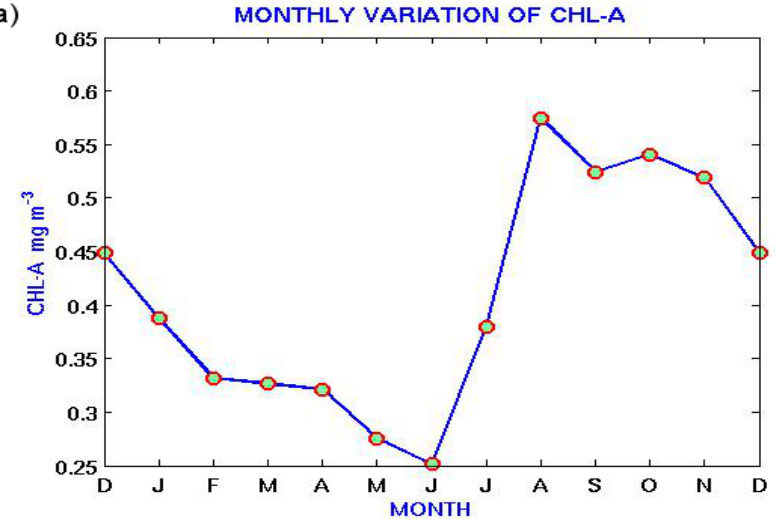

c)

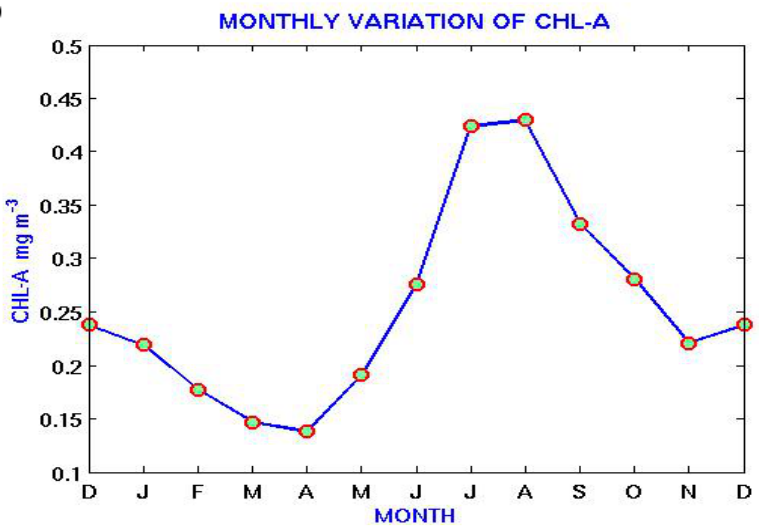

b)

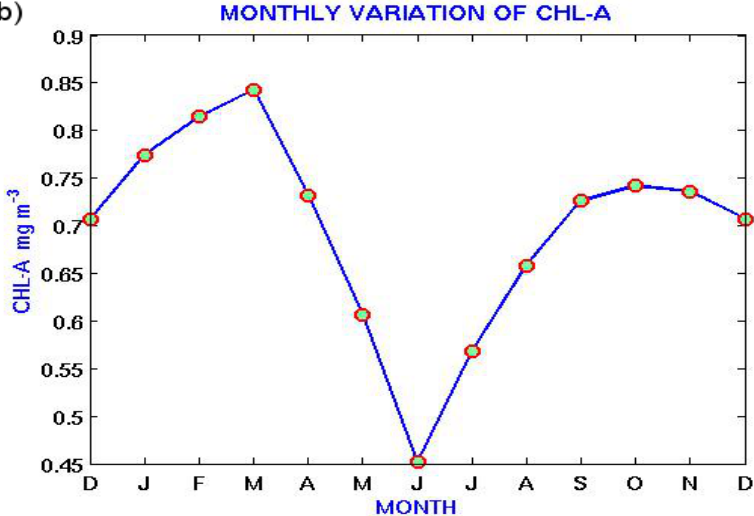

d)

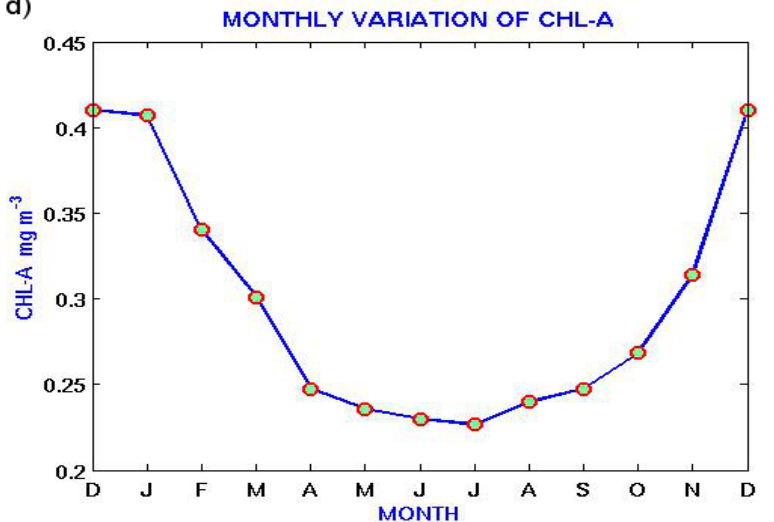

Fig. 6 Monthly mean of surface Chl $a$ for (a) Box A, (b) Box B, (c) Box C and (d) Box D.

a)

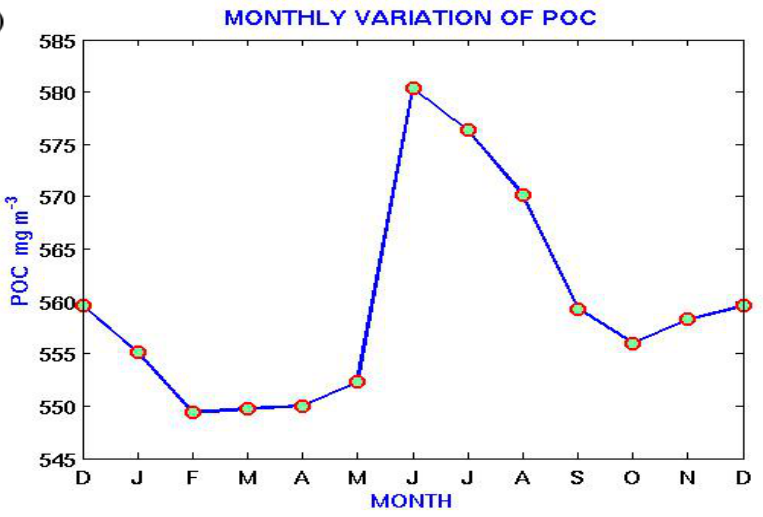

c)

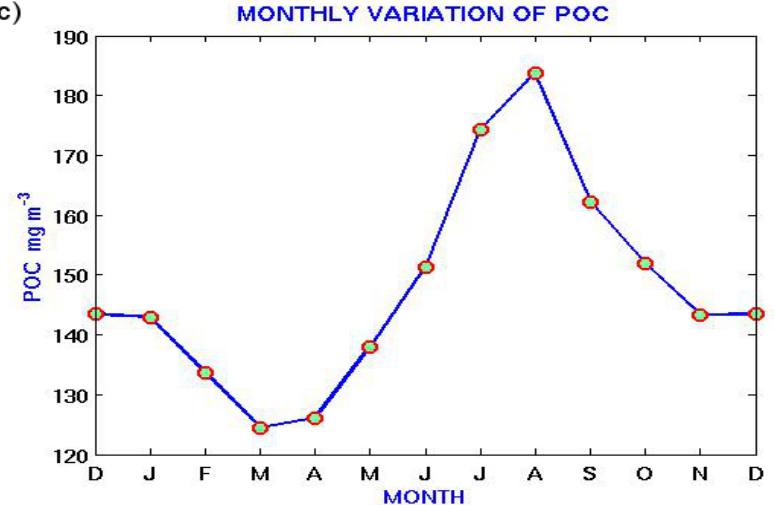

b)

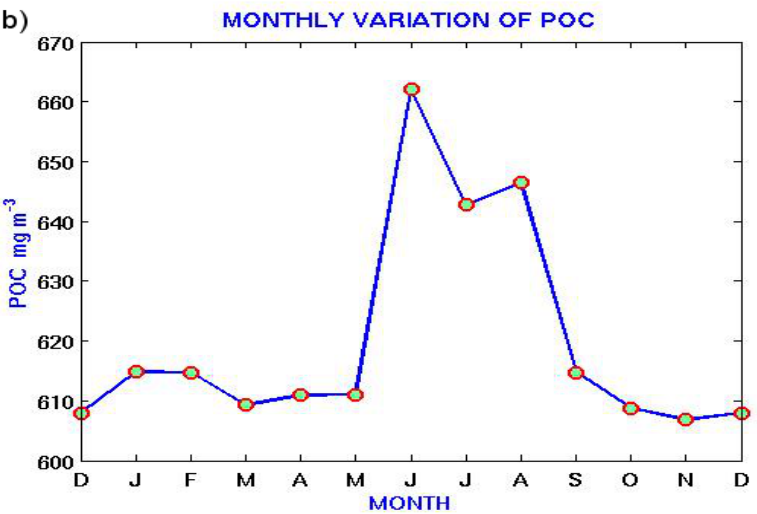

d)

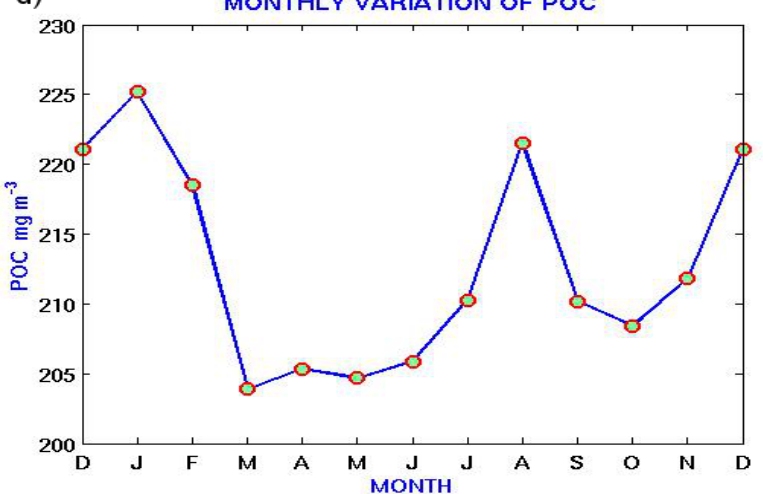

Fig. 7 Monthly mean of surface POC for (a) Box A, (b) Box B, (c) Box C and (d) Box D. 
by upwelling of nitrate rich waters towards surface which influences the biological activity of that region. Box A and Box C of Fig. 8 illustrate strong correlation between Nitrate and EPV. Phosphate (Fig. 10) and silicate (Fig. 12) also show a positive correlation in Box A. EPV is high in July, August in Box A and Box $\mathrm{C}$ which supplement nutrient from subsurface layer to the surface layer and thus influence the Chl $a$ bloom in these regions.

\subsection{Relation of Nutrients with SSH}

Nitrate is negatively correlated with SSH (Fig. 9) during the northeast monsoon except for the month of February. SSH positive denotes downwelling and is accompanied by nutrient-poor warm water. SSH negative denotes upwelling and is usually accompanied by nutrient-rich cold water. The cyclonic

a)

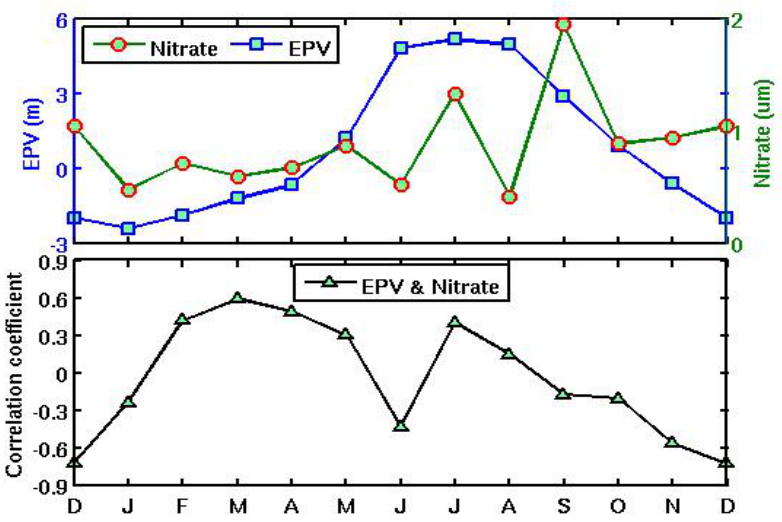

c)

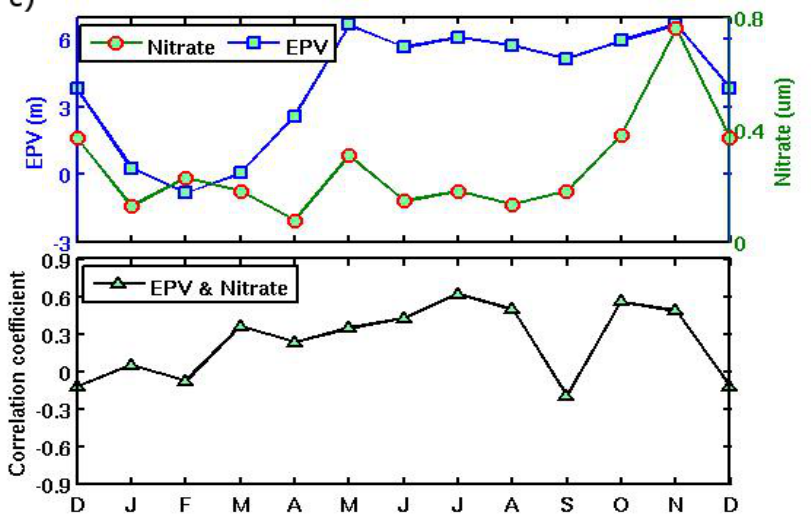

circulation in the northern $\mathrm{BOB}$ showed negative correlation with SSH. Large variations are observed during the monsoon in all boxes of nitrate (Fig. 9), phosphate (Fig. 11) and silicate (Fig. 13). The Boxes $\mathrm{C}$ and $\mathrm{D}$ are mostly negatively correlated in the regions during pre-monsoon and monsoon. The negative correlation coefficients are found where high nutrient discharge has been found in regions near the eastern and western coast of BOB. It has been examined from Box $\mathrm{A}$ and Box $\mathrm{C}$ that during August, there is an enormous flux of phosphate and silicate whereas SSH is also high but negative correlation is observed in case of nitrate. This is due to the influence of huge freshwater discharge from the adjoining rivers in the head $\mathrm{BOB}$ during August, which is accompanied by phosphate and silicate flux.

b)

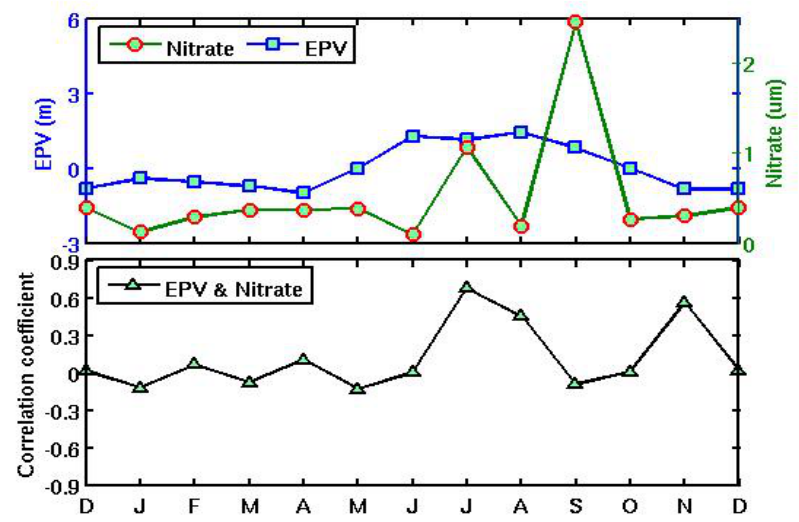

d)

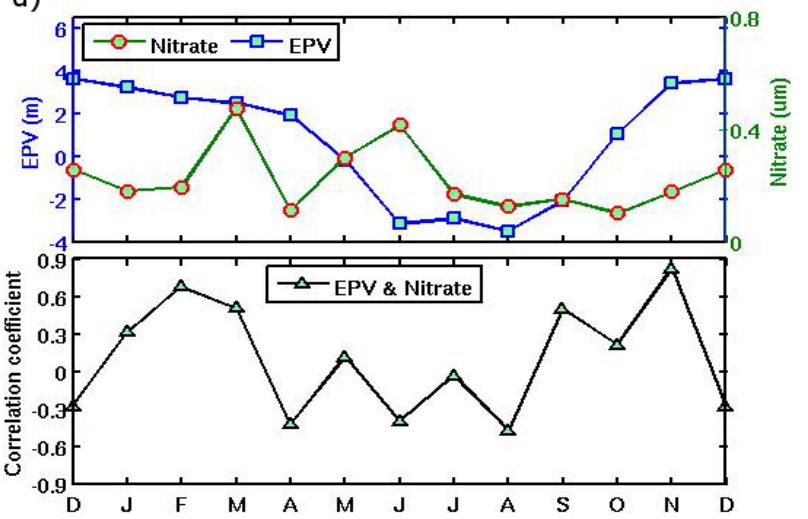

Fig. 8 Monthly variations of nitrate and EPV (upper panel) and corresponding correlation (lower panel) for (a) Box A, (b) Box B, (c) Box C and (d) Box D. 
a)

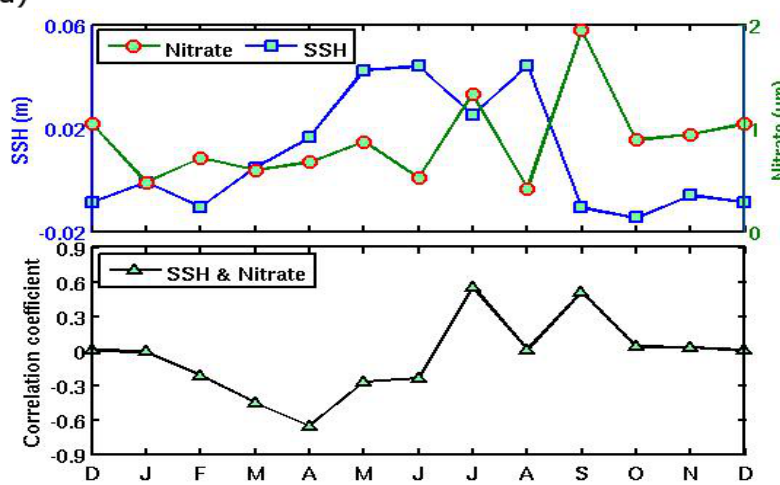

c)
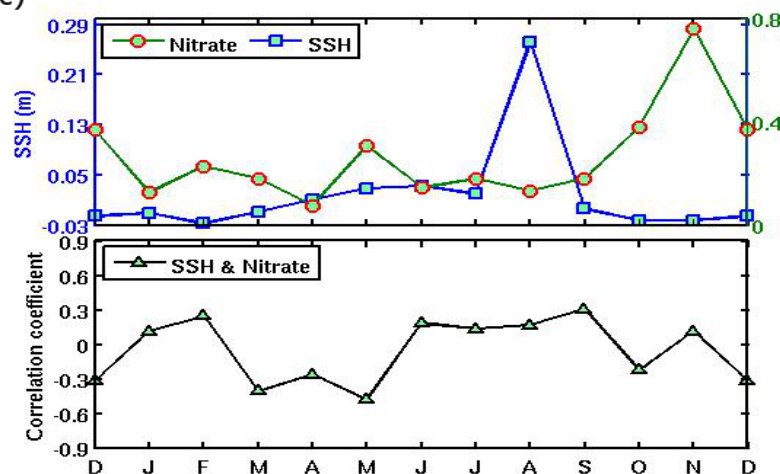

b)

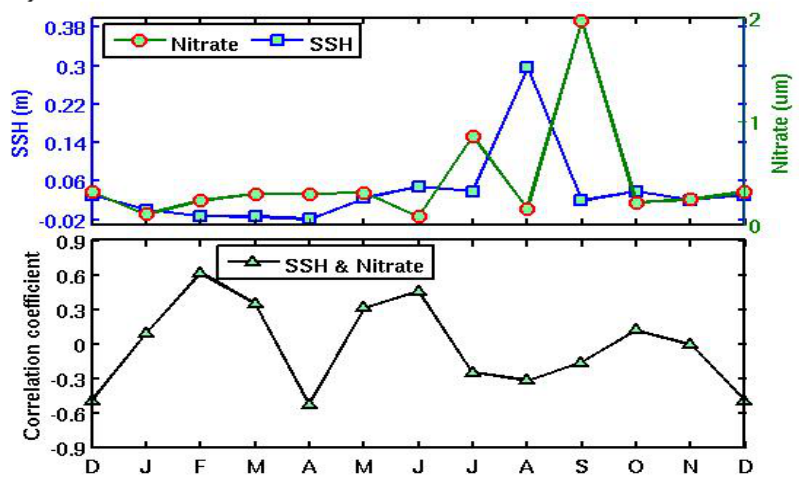

d)

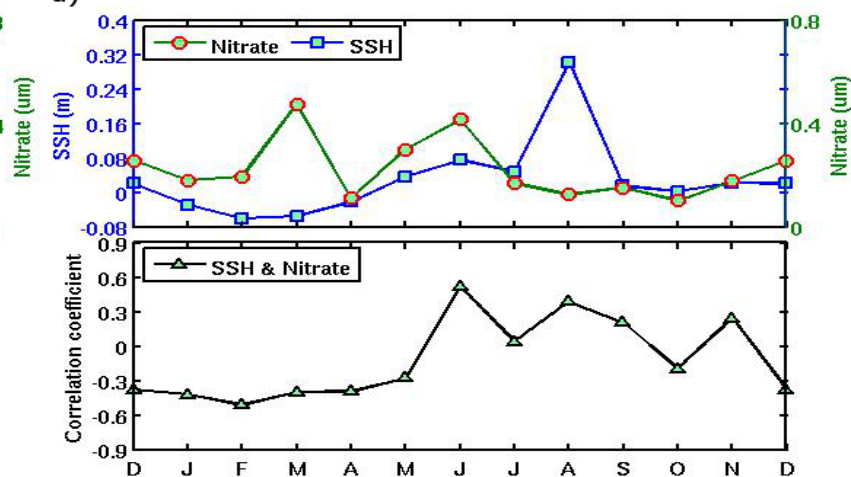

Fig. 9 Monthly variations of nitrate and SSH (upper panel) and corresponding correlation (lower panel) for (a) Box A, (b) Box B, (c) Box C and (d) Box D.

a)
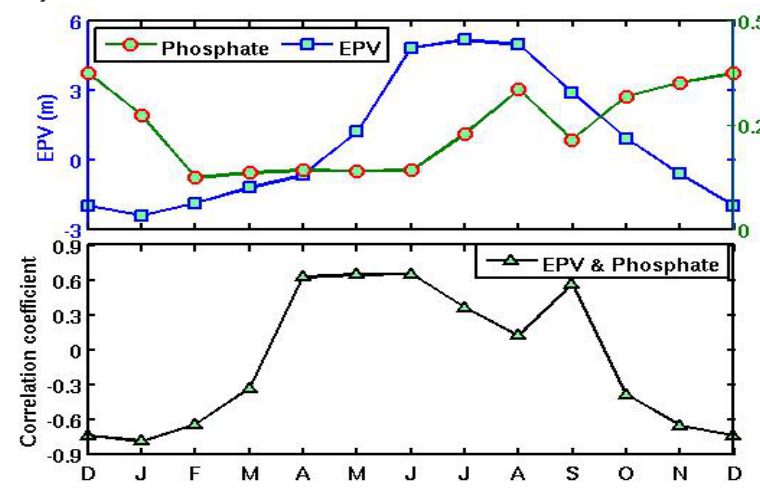

c)

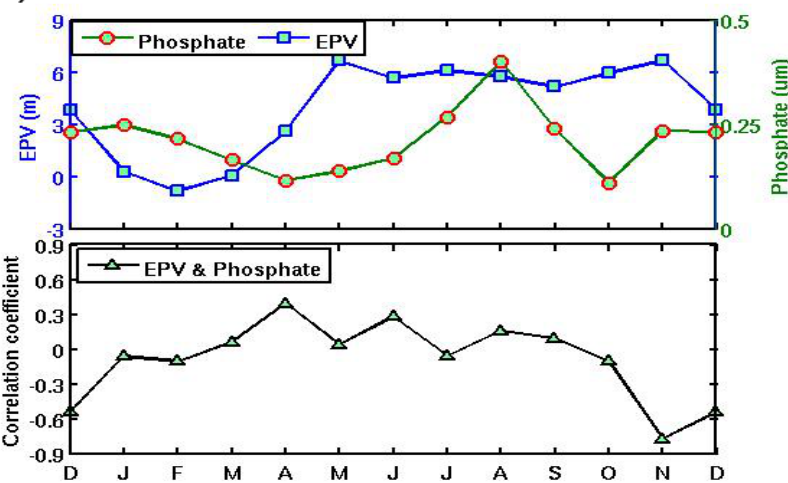

b)

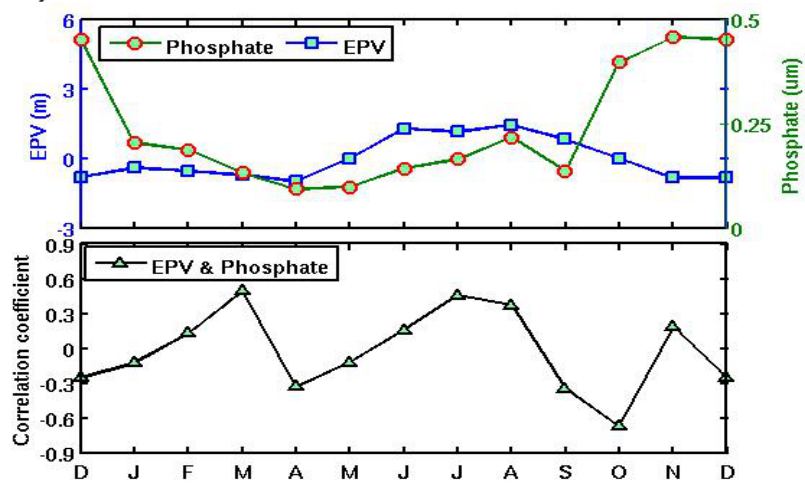

d)

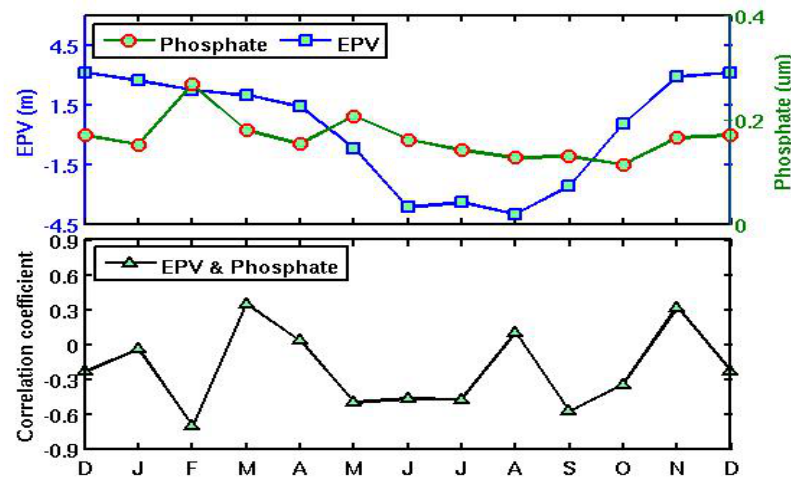

Fig. 10 Monthly variations of phosphate and EPV (upper panel) and corresponding correlation (lower panel) for (a) Box A, (b) Box B, (c) Box C and (d) Box D. 


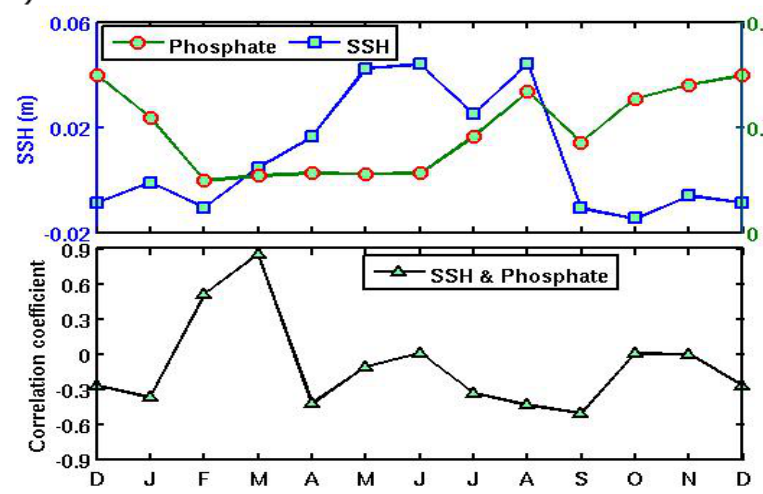

c)

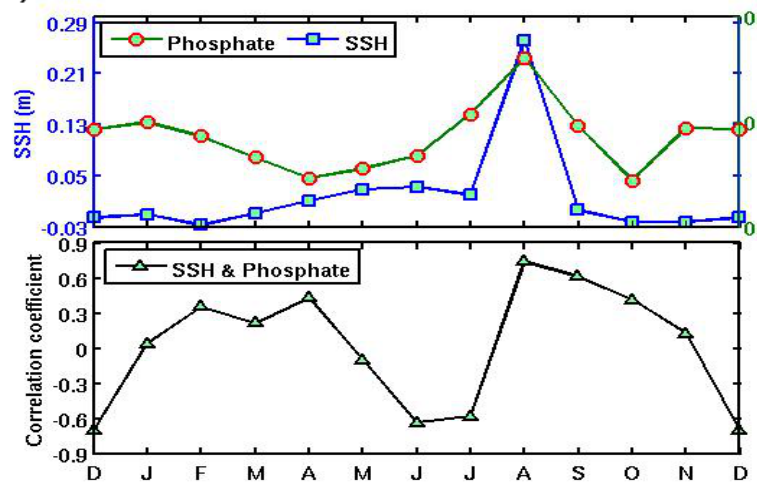

b)

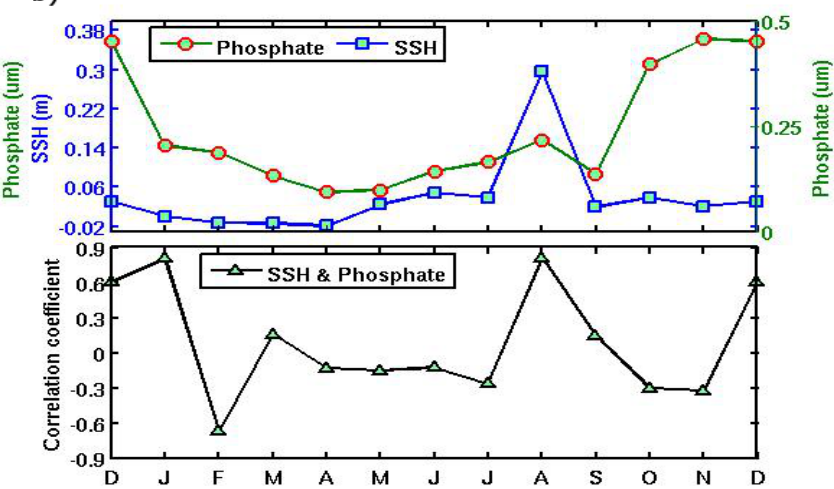

d)

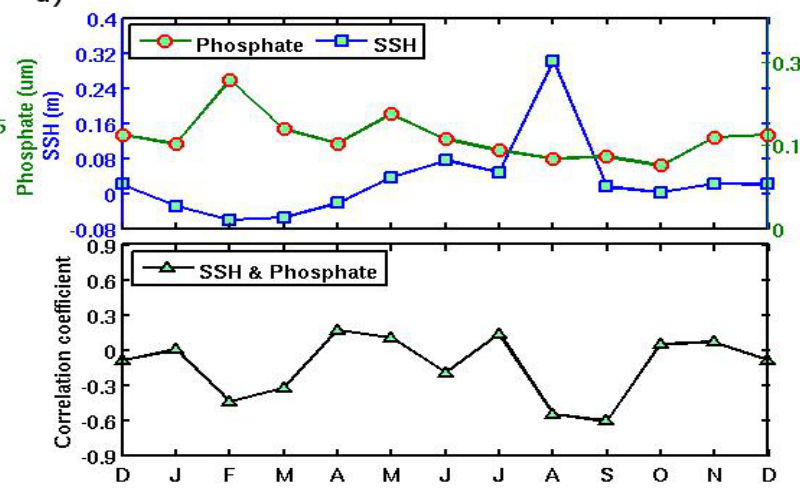

Fig. 11 Monthly variations of phosphate and SSH (upper panel) and corresponding correlation (lower panel) for (a) Box A, (b) Box B, (c) Box C and (d) Box D.

a)

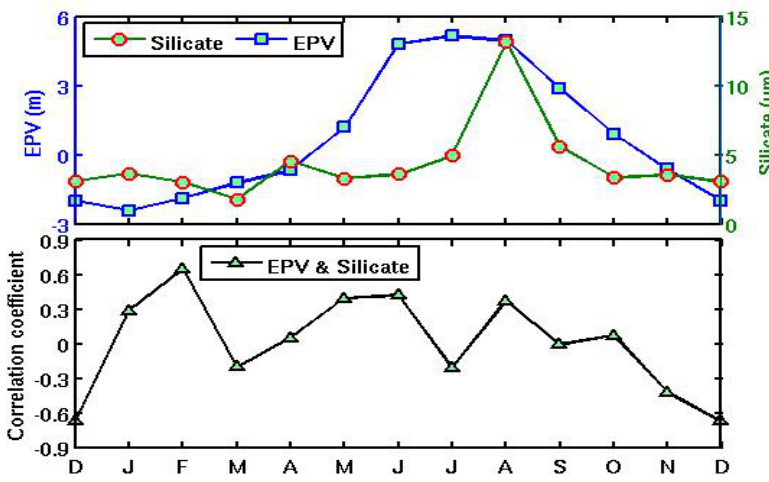

c)

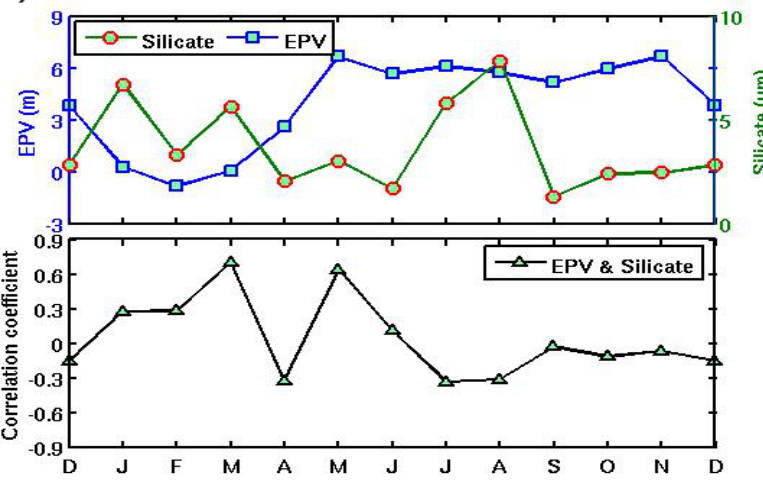

b)

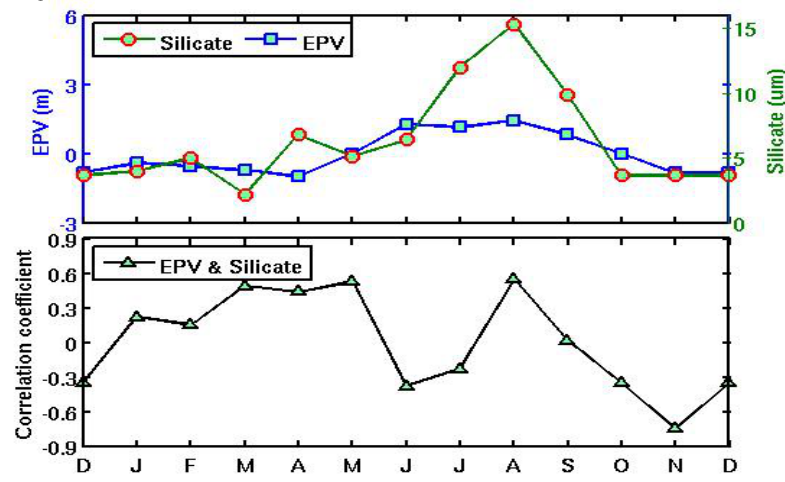

d)

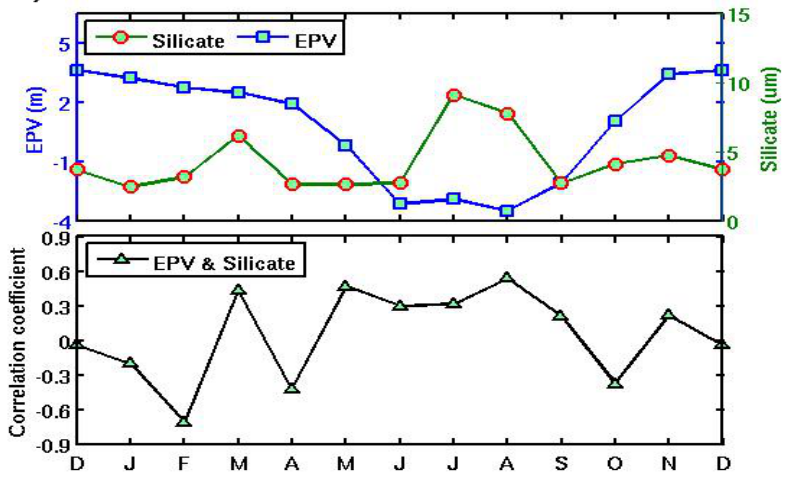

Fig. 12 Monthly variations of silicate and EPV (upper panel) and corresponding correlation (lower panel) for (a) Box A, (b) Box B, (c) Box C and (d) Box D. 
a)

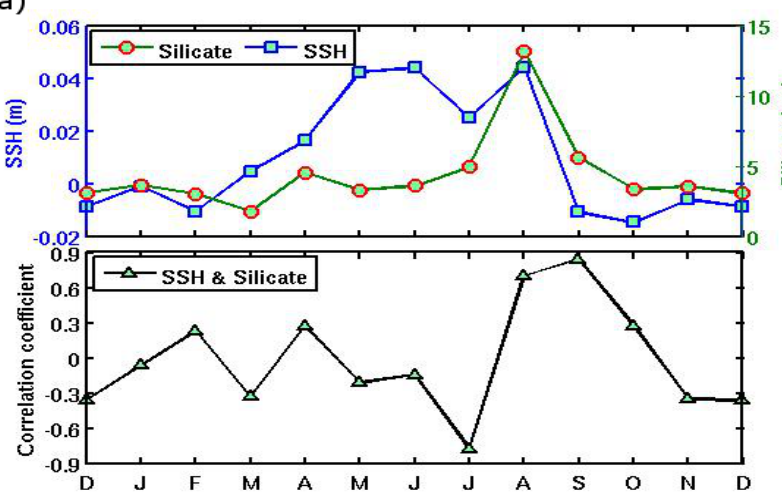

c)

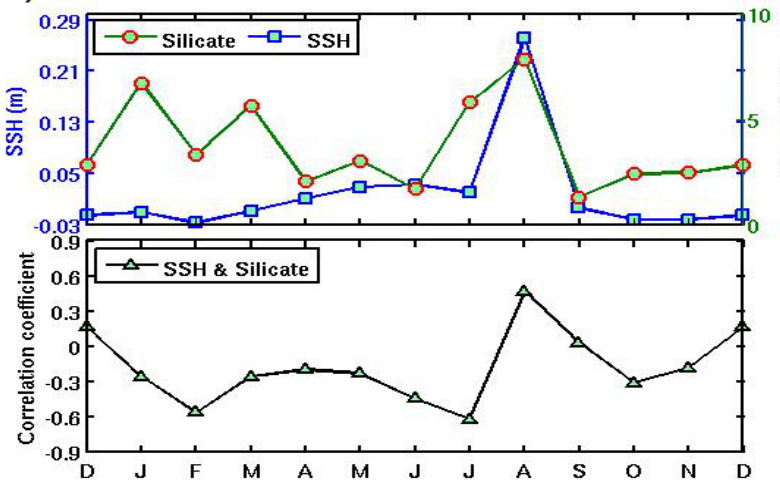

b)

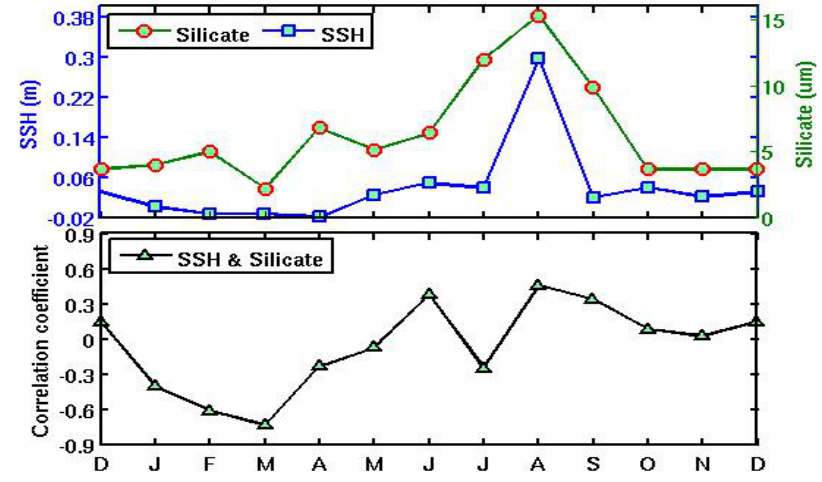

d)

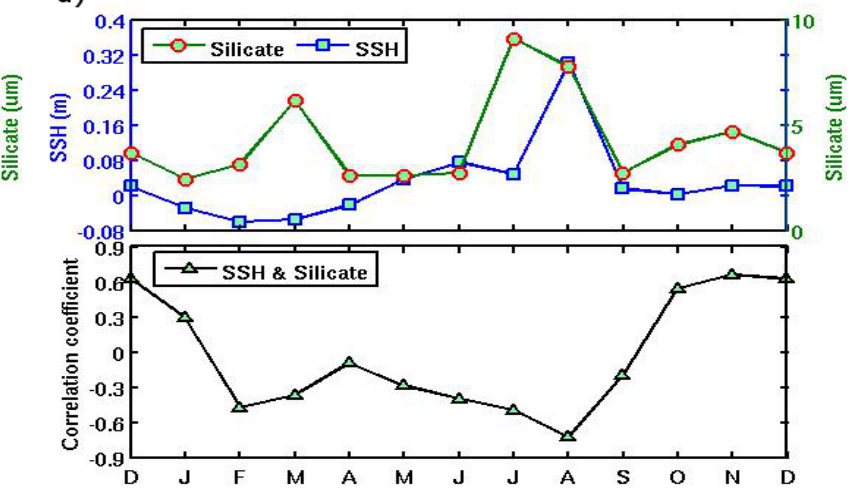

Fig. 13 Monthly variations of silicate and SSH (upper panel) and corresponding correlation (lower panel) for (a) Box A, (b) Box B, (c) Box C and (d) Box D.

\section{Conclusions}

In this study, we have used WOA13 (0.25 degree) for nutrients and SODA (0.5 degree) for currents to develop high resolution $(5 \mathrm{~km} \times 5 \mathrm{~km})$ climatology dataset of nutrients and currents for the BOB called Nutrient-Climo. These new climatology data provide us high resolution and good-quality data of nutrients and current at near shore where the data are limited.

The nutrient-rich region in the $\mathrm{BOB}$ has been examined with ocean currents from the SODA package. This high resolution nutrient dataset is sufficient, to some extent, producing the nutrient rich zones compatible with coastal upwelling regions. The biological response has been analyzed from the $\mathrm{Chl} a$ concentration and POC from SeaWiFS data and MODIS data respectively. The correlation coefficient between nitrate and physical parameters (EPV and $\mathrm{SSH}$ ) has been analyzed in this paper. Positive correlation has been found between Nitrate and $\mathrm{EPV}$ in these four boxes which indicated nutrient-rich regions that are linked with upwelled zones. These oceanic components may lead to identifying the potential productive zones in the BOB. During June, nutrients in the mixed layer cannot come up due to high static stability of $\mathrm{BOB}$, so $\mathrm{Chl} a$ concentration is also low in this region. In this paper, it has been also observed that $\mathrm{Chl} a$ bloom (above $0.8 \mathrm{mg} / \mathrm{m}^{3}$ ) is found in the near shore compared to the open ocean during October-November followed by March-April in the western and eastern $\mathrm{BOB}$ respectively. The $\mathrm{Chl} a$ concentration is high when nitrate and phosphate concentration are also in appreciable amount during the post-monsoon. Especially in the head and the eastern coast of Bay the source of nutrients is much more due to high input of litter and sediment associate nutrients that are released during estuarine transport [18]. The silicate flux is observed high (above 16 $\mu \mathrm{mol} / \mathrm{L}$ ) towards the northeast and head of the BOB in July, August and September resulting from the influx of various rocks weathering material carried by 
different river sources. During the summer monsoon, anticyclonic circulations in the southern BOB, showed positive correlation between nutrients and EPV and the cyclonic eddy in the northern BOB, supplemented with nutrient-rich water, showed positive correlation with EPV and negative correlation with SSH. Many small scale mesoscale features which also help in influencing the biological response are observed in this paper. Analyzing and understanding the complete nutrient distribution helps in the future development of high resolution biophysical model for the BOB which will make precise the regional biological response and ecology for identifying intense fishing zone.

\section{Acknowledgments}

This work was supported in part by the Indian National Centre for Ocean Information Services (RCP/2013) Hyderbad, India.

\section{References}

[1] Legeckis, R. 1987. "Satellite Observations of a Western Boundary Current in the Bay of Bengal." Journal of Geophysical Research 92: 12974-8.

[2] Shetye, S. R., Gouveia, A. D., Shankar, D., Shenoi, S. S. C., Vinayachandran, P. N., Sundar, D., Michael, G. S., and Nampoothiri, G. 1996. "Hydrography and Circulation in the Western Bay of Bengal during the Northeast Monsoon." Journal of Geophysical Research 101: 14011-25.

[3] Schott, F. A., and McCreary, J. P. 2001. "The Monsoon Circulation of the Indian Ocean." Progress in Oceanography 51: 1-123.

[4] Cutler, A. N., and Swallow, J. C. 1984. "Surface Currents of the Indian Ocean (to 25S, 100E): Compiled from Historical Data Archived by the Meteorological Office, Bracknell, UK." Institute of Oceanographic Sciences, Wormley, UK.

[5] Prasanna Kumar, S., Muraleedharan, P. M., Prasad, T. G., Gauns, M., Ramaiah, N., de souza, S. N., and Madhupratap, M. 2002. "Why Is the Bay of Bengal Less Productive during Summer Monsoon Compared to the Arabian Sea?" Geophysical Research Letters 29: 2235.

[6] Fernandes, V., Ramaiah, N., Sardessai, S., Jyoti Babu, R., Mangesh, G., and Paul, J. T. 2008. "Strong
Variability in Bacterioplankton Abundance and Production in Central and Western Bay of Bengal." Marine Biology 153 (5): 975-85.

[7] Rao, C. K., Naqvi, S. W. A., Kumar, M. D., Varaprasad, S. J. D., Jayakumar, D. A., George, M. D., and Singbal, S. Y. S. 1994. "Hydrochemistry of Bay of Bengal: Possible Reasons for a Different Water-Column Cycling of Carbon and Nitrogen from the Arabian Sea." Marine Chemistry 47: 279-90.

[8] Muraleedharan, K. R., Jasmine, P., Achuthankutty, C. T., Revichandran, C., Dinesh Kumar, P. K., Anand, P., and Rejomon, G. 2007. "Influence of Basin-Scale and Mesoscale Physical Processes on Biological Productivity in the Bay of Bengal during the Summer Monsoon." Progress in Oceanography 72: 364-83.

[9] Vinayachandran, P. N., and Mathew, S. 2003. "Phytoplankton Bloom in the Bay of Bengal and Its Intensification by Cyclones." Geophysical Research Letters 30 (11): 1572.

[10] Ritthirong, P., Pirote, N., and Natinee, S. 2008. "Distribution of Nutrients in the Bay of Bengal." The Ecosystem-Based Fishery Management in the Bay of Bengal. BIMSTEC Project Survey 75-1/2007: 33-44.

[11] Garcia, H. E., Locarnini, R. A., Boyer, T. P., Antonov, J. I., Baranova, O. K., Zweng, M. M., Reagan, J. R., and Johnson, D. R. 2014. "World Ocean Atlas 2013, Volume 4: Dissolved Inorganic Nutrients (Phosphate, Nitrate, Silicate)." S. Levitus, Ed., A. Mishonov Technical Ed.; NOAA Atlas NESDIS 76: 25.

[12] Carter, E. F., and Robinson, A. R. 1987. "Analysis Models for the Estimation of Oceanic Fields." Journal of Atmospheric and Oceanic Technology 4: 49-74.

[13] Lozano, C. J., Robinson, A. R., Arango, H. G., Gangopadhyay, A., Sloan, N. Q., Haley, P. J., and Leslie, W. G. 1996. “An Interdisciplinary Ocean Prediction System: Assimilation Strategies and Structured Data Models." In Modern Approaches to Data Assimilation in Ocean Modelling, edited by Malanotte-Rizzoli, P. Elsevier Oceanography Series, Elsevier, The Netherlands, 413-52.

[14] Kumar, B. 2011. "Analysis of Oceanic Heat Content in the Bay of Bengal." Ph.D thesis, Indian Institute of Technology, Kharagpur, India.

[15] Levy, M., Shankar, D., Andre, J. M., Shenoi, S. S. C., Durand, F., and Montegut, C. de Boyer. 2007. "Basin-Wide Seasonal Evolution of the Indian Ocean's Phytoplankton Blooms." Journal of Geophysical Research 112: C12014.

[16] Deb, S., and Chakraborty, A. 2009. "Seasonal Variations of Dissolved Oxygen in the Bay of Bengal." Indian Journal of Polar Science 2: 11-30.

[17] Deb, S., and Chakraborty, A. 2015. "Simulating the 
Effects of Tidal Dynamics on the Biogeochemistry of the Hooghly Estuary." IEEE Journal of Selected Topics in Applied Earth Observations and Remote Sensing 8:
$130-40$.

[18] Subramanian, V. 1993. "Sediment Load of the Indian Rivers." Current Science 64: 928-30. 